\title{
Epoxy nanocomposites filled with carbon nanostructures
}

M. Martin-Gallego ${ }^{a}$, V. Yuste-Sanchez ${ }^{a}, R$.

Sanchez-Hidalgo ${ }^{\mathrm{a}, \mathrm{b}}, \mathrm{R}$. Verdejo ${ }^{\mathrm{a}}$, M.A. Lopez-

Manchado a*

Dedicated to Prof. Eduardo Ruiz-Hitzky, a great scientist and a

better person with whom we had the pleasure to work with.
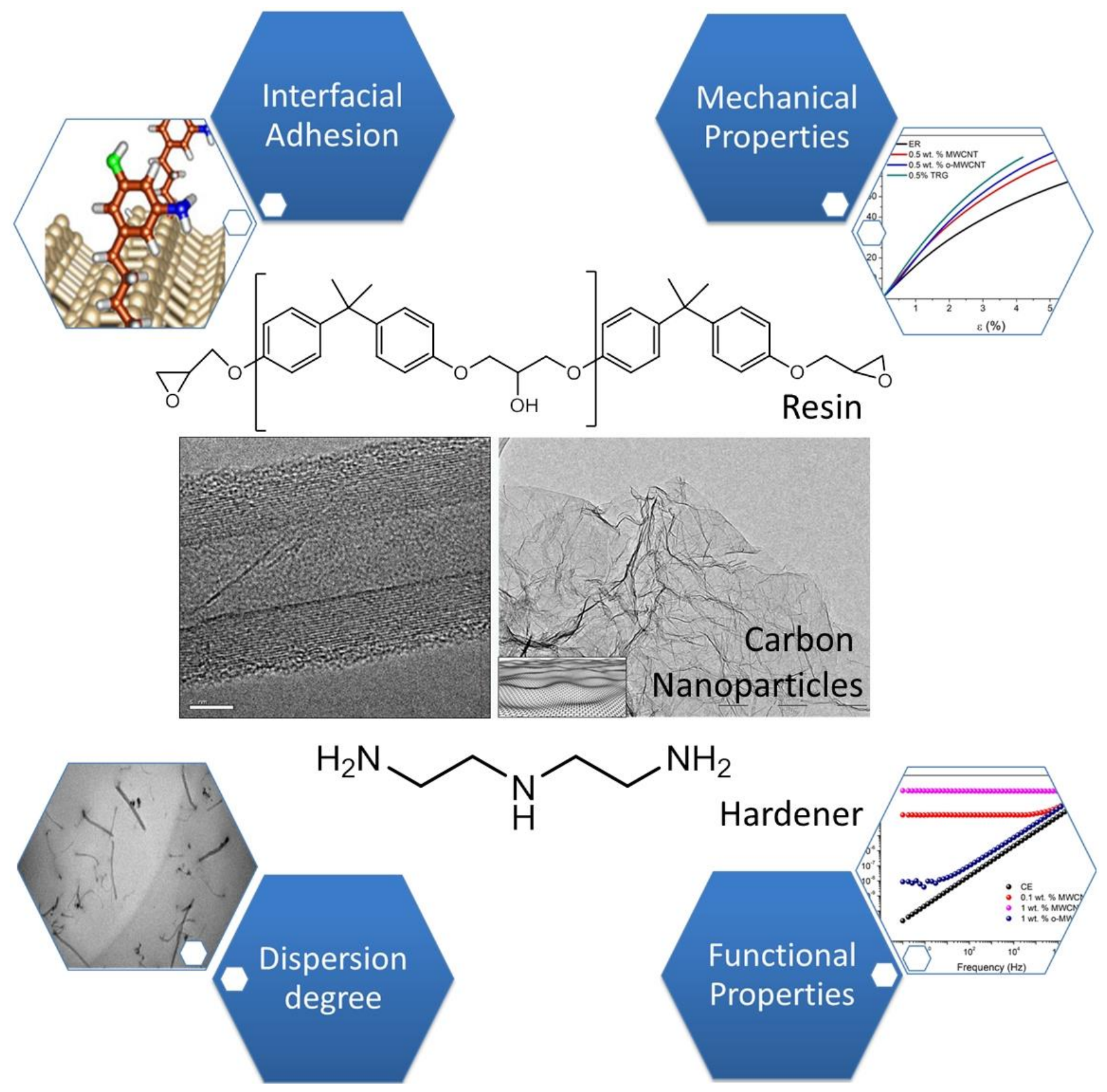


\section{Abstract:}

Over the past decades, the development of high performance lightweight polymer nanocomposites and, in particular, of epoxy nanocomposites has become one the greatest challenges in material science. The ultimate goal of epoxy nanocomposites is to extrapolate the exceptional intrinsic properties of the nanoparticles to the bulk matrix. However, in spite of the efforts, this objective is still to be attained at commercially attractive scales. Key aspects to achieve this are ultimately the full understanding of network structure, the dispersion degree of the nanoparticles, the interfacial adhesion at the phase boundaries and the control of the localization and orientation of the nanoparticles in the epoxy system. In this Personal Account, we critically discuss the state of the art and evaluate the strategies to overcome these barriers.

\section{Introduction}

Epoxy resins are thermoset systems, which have their properties mainly governed by the polymer network structure formed through a polymerization reaction. This network can be tailored by an appropriate choice of the curing agent, being amines the most commonly used ${ }^{1}$. This leads to a versatile material with excellent thermomechanical properties, good heat and chemical resistances, low density, and high adhesiveness to many substrates. Hence, epoxy resins are intensively used across as adhesives, coatings or matrix in fiber composites in a wide range of fields, such as automotive, aerospace, and electronic devices. However, they present some drawbacks like their high brittleness, high tendency to uptake water, their polymerization shrinkage, and relatively high thermal expansion coefficient ${ }^{2}$. Inorganic microscale fillers have been used to solve these limitations but, in general, high filler contents were needed, which led to a dramatically reduction of the mechanical properties and a sensible increase in the material density.

Over the past decades, the use of nanostructured fillers in epoxy systems has gained significant importance in the development of thermosetting composites. The incorporation of nanoparticles allows the desired properties to be achieved at low loading fractions and, therefore, limits their negative effects. The nanofillers are characterized by a high specific surface area (SSA) and long aspect ratio. In addition, they also have exceptional intrinsic mechanical, electrical, thermal, optical, electrochemical and catalytic properties. The nanoparticles most commonly used are: titania, silica, carbon nanotubes (CNTs), carbon nanofibers (CNFs), graphene, fullerenes, nanoclays, cellulose nanowhiskers and magnetite ${ }^{3,4}$. The combination of

[a] Dr. M. Martin-Gallego, Miss V. Yuste-Sanchez, Dr. Raquel Verdejo, Prof. M.A. Lopez-Manchado

Instituto de Ciencia y Tecnologia de Polimeros, ICTP-CSIC

Consejo Superior de Investigaciones Cientificas

C/ Juan de la Cierva, 3 Madrid, 28006, Spain

E-mail: Imanchado@ictp.csic.es

http://www.nanocomp.ictp.csic.es/

[b] Mr. R. Sanchez-Hidalgo

Instituto del Carbon, INCAR-CSIC

Consejo Superior de Investigaciones Cientificas

C/ Francisco Pintado Fe, 26 Oviedo, 33011, Spain their structural and intrinsic properties is used to modify the properties of epoxy systems or to introduce new functionalities. However, despite their exceptional intrinsic properties, efficiently extrapolating these properties to the matrix has become the greatest challenge of nanocomposite development. The key aspects to overcome this challenge are the full understanding of network structure, the dispersion degree of the nanoparticles, the interfacial adhesion at the phase boundaries and the control of the localization and orientation of the nanoparticles in the epoxy system. This review provides a systematic overview of the main aspects involved in the fabrication and properties of carbon nanoparticles-epoxy nanocomposites.

Mario Martín-Gallego finished his PhD in material
engineering in 2015 . His thesis is based on the addition
of carbon nanotubes and graphene in different epoxy
formulations: epoxy foams, nanostructured polymers,
UV curable resins and thermally cured epoxy resins.
Even before he defended his Thesis, Mario started to
work in the industry as the R\&D and production manager
of rubber compounds in a Spanish SME. Nowadays,
Mario holds a position as project manager in the
innovation department of a Spanish multinational
company.

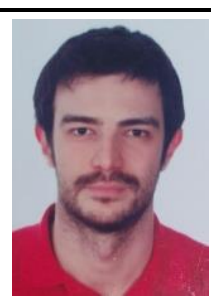

Vanesa Yuste-Sánchez is currently pursuing her Ph.D. in the Polymer Composite Group at the Institute of Polymer Science and Technology Institute, Spanish National Research Council (CSIC), Spain. She holds a Chemical Engineer BSc, and a MSc in High Specialization in Plastics and Rubber from the Menendez Playo International University in 2015. Her work is focused on the development of epoxy composites for capacitive sensors, and her research area of interest is the different strategies of incorporating of new fillers into nanocomposites for electric applications.

Rubén Sánchez-Hidalgo is currently a PhD student in Materials Science in the National Institute of Coal (Oviedo) and Institute of Polymer Science and Technology (Madrid), Spanish National Research Council (CSIC). He received the BSc and MSc degrees in Chemistry from the University of Salamanca in 2011 and 2012, respectively. His current research includes the preparation and structural characterization of graphene materials with controlled properties and their influence as reinforcement in both epoxy resin and silicone rubber composites.

Dr. Raquel Verdejo is Research Scientist at ICTPCSIC (Spain). She got her MSc in Physics from the University of Valladolid (Spain) and her PhD in Metallurgy and Materials from the University of Birmingham (UK). She then joined the group lead by Prof. Milo Shaffer as a Research Associate at Imperial College London. After that, she moved back to Spain and joined ICTP-CSIC in 2006 thanks to a Juan de la Cierva contract and then, held a Ramón y Cajal contract. She works on both foamed and bulk polymer (nano)composites.

Dr. Lopez-Manchado is Research Professor at ICTPCSIC. He got his $\mathrm{PhD}$ in Chemistry at the University Complutense of Madrid in 1997. From 1998-2000, he did a postdoctoral stay at University of Perugia. He is author of more than 150 publications in scientific journals and books, with more than 7200 citations and h-index 45 . He works in the processing and characterization of composite materials and nanocomposites.
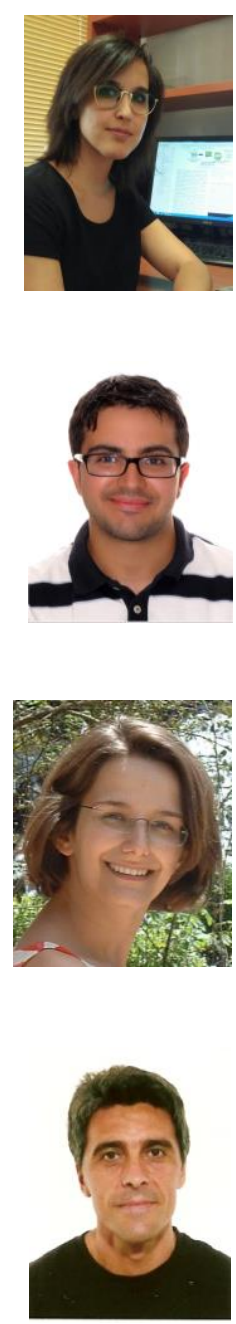


\section{Production of epoxy nanocomposites 2.1 Dispersion of the CNPs}

The biggest challenge in order to attain the desired nanocomposite properties is to disperse the nanoparticles as individual particles in the epoxy matrix. However, nanoparticles easily form agglomerates due to adhesive forces. Furthermore, these forces increase with increasing SSA and decreasing particle size. Poor dispersion of CNTs not only dramatically reduces their reinforcing efficiency, caused by the CNTs slipping by each other when forces are applied, but also results in the formation of micro-voids in the nanocomposites ${ }^{5}$. Therefore, the way to disperse nanofillers into individually separated particles is considered the most important stage in nanocomposite processing. To date, several strategies have been used to disperse nanoparticles in epoxy matrices, such as ultrasonic methods, low and high shear mixing and functionalization of the nanoparticles. From personal experience and in agreement with other authors, shear-mixing involving a three-roll mill or calender (Figure 1) has been the most effective method to achieve a homogeneous dispersion of nanofillers into resin ${ }^{6-10}$.

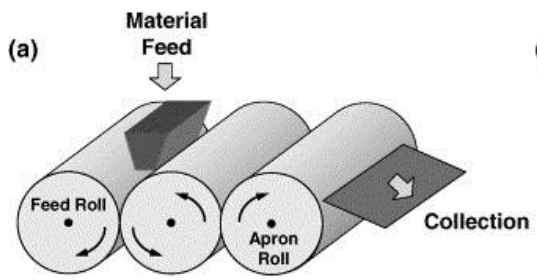

(b)

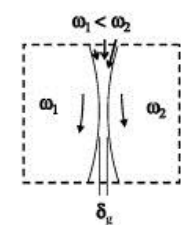

Figure 1. a) Schema of the three roll calendering, b) high shear zone between rolls. Reprinted with permission from Elsevier ${ }^{7}$

This method involves passing the mixture through the gaps of parallel contra-rotating rollers at different angular velocities, which exert uniform high shear forces and favor the homogenization of the mixture. Vazquez-Moreno ${ }^{10}$ established an optimal processing protocol with three cycles where the roll gap decreased progressively while increasing their speed and cycle time. Such protocol included the observation of the liquid suspensions by optical microscopy to discriminate the best dispersion state. Prolongo et al. ${ }^{11}$ compared three approaches to dispersed GNPs in an epoxy resin, high-shear mixing, calendaring, and a combination of both. They observed that high-shear mixing resulted in a reduction of the GNPs lateral size by breakage, which could also increase their structural defects. Meanwhile, the calendering process was more effective and induced a partial exfoliation of the GNPs reducing their thickness from 20-30 nm to 2-3 nm.

\subsection{Cure reaction}

The performance of epoxy-based composites strongly depends on the network structure formed during the curing reaction. Hence, it is essential to study the effects of the addition of nanoparticles on the curing kinetics ${ }^{12}$. Calorimetry is one of the most commonly employed techniques for the analysis of the curing reaction in epoxy resins. Recently, we have developed a new approach based on multiple-quantum NMR experiments performed in low-field spectrometers to obtain the extent of reaction. These experiments provide molecular evidence on the evolution of epoxy resins during the curing process, being especially sensitive to the final stages of the reaction where the DSC does not provide information. By optimizing the pulse sequence, we were able to establish the kinetic parameters of the epoxy cure reaction, such as induction time, vitrification time, polymerization rate and activation energy ${ }^{13}$.

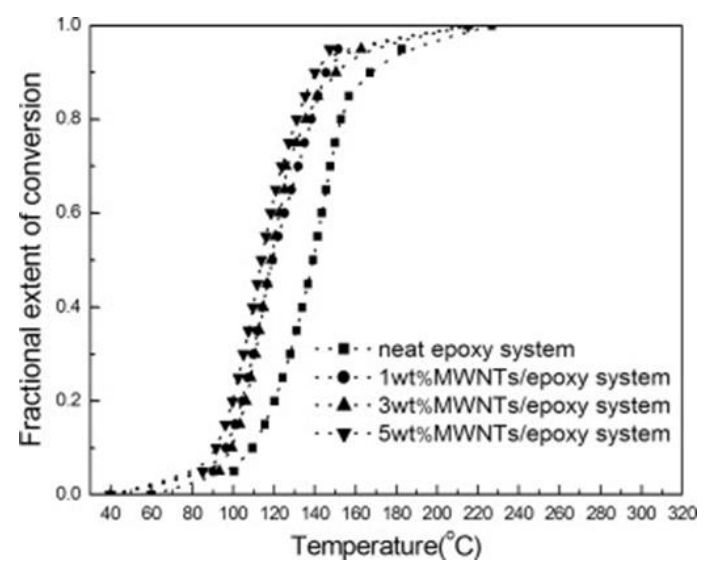

Figure 2. Extent of reaction vs temperature at $20{ }^{\circ} \mathrm{C} / \mathrm{min}$ of MWCNTs filled epoxy systems. Reprinted with permission from Elsevier ${ }^{16}$

Independently of the type of curing agent, amine, thiols, alcohols or anhydrides, the curing reaction takes place via oxirane ring opening through the nucleophilic addition reaction. Hence, the conversion-temperature curves, obtained by traditional dynamic DSC scans, often follow a sigmoidal form, which indicates autocatalytic reaction kinetics. There is still some controversy on the effect of CNPs in the kinetics of epoxy curing. Most authors have reported that the incorporation of carbon nanoparticles facilitates crosslinking (Figure 2) by decreasing the heat of reaction $\left(\Delta H_{r}\right)$ and the exothermic peak temperature ${ }^{14-18}$, which has been ascribed to the high thermal conductivity of the CNTs and the ability of the epoxy resin to open the CNT bundles creating a higher surface for heat propagation. However, other authors have observed that the addition of CNTs hinders the crosslinking reaction between the epoxy and hardener, ascribed to decrease of the fluidity of system ${ }^{19,20}$. DSC results indicated that the level of residual unreacted epoxy increased gradually with the addition of CNTs, related to the formation of bundles and aggregates at high loading levels. This reduction of overall degree of cure caused a sensible reduction in the glass transition temperature and the thermal stability of the composites. This discrepancy can be explained considering two possible arguments. First, the loading fraction can have an effect on the curing reaction and, second, the surface functionality of the CNPs should also be considered. Prolongo et al. ${ }^{21}$ observed that the incorporation of up to $5 \mathrm{wt} . \%$ of GNP did not have any catalytic effect, which was ascribed to the steric hindrance of GNPs that impedes the mobility of the reactants. Meanwhile, the 
addition of 5 wt.\% GNPs accelerated the curing reaction of DGEBA. They concluded that the higher thermal conductivity of the sample with large GNPs concentrations overcomes the hindrance effect. We, on the other hand, have studied the effect of the surface functionality of the CNPs on the cure kinetics ${ }^{9}$. We analyzed the effect of thermally reduced graphite oxide (TRGOs) at different temperatures, from 700 to $2000^{\circ} \mathrm{C}$, since they present different concentrations of functional groups on its structure $^{22}$. TRGOs reduced at low temperatures, which have a large concentration of carbonyl, hydroxyl and epoxy on its structure, caused an acceleration of the curing reaction of an epoxy resin. Meanwhile, those reduced at high temperatures, which have almost none residual functional groups, showed a similar rate than the epoxy resin. Other authors have also seen a similar catalytic behavior by adding graphene oxide, which has the highest concentration of functional groups ${ }^{23}$. Hence, the presence of any type of functionality can result in a catalytic behavior of the CNPs.

A strategy to improve the dispersion state of the CNPs and the interfacial adhesion at the phase boundaries has been the surface functionalization of the CNPs, which should in turn result in enhanced physical properties. However, covalent modification of the CNPs might also influence not only the rate of the crosslinking reaction of the epoxy resins but also the type of the curing reaction. A variety of techniques and functional groups have been employed to functionalize CNTs ${ }^{24-27}$. Among them, the carboxylation, halogenation, and amidation are the most commonly used methods for enhancing structural properties of CNT/epoxide composites. In general, functionalized MWCTNs bearing reactive groups located on their surface and at defect sites promote the nanofiller reactivity, acting as curing agents and accelerating the cure reaction of epoxy. Abdalla et al. ${ }^{24}$ investigated the effect of carboxyl and fluorine surface modification of CNTs on the curing behavior of epoxy resins. They reported that the cure mechanism of the neat epoxy and fluorinated systems was very similar, with cure heats of 47.5 and $47.7 \mathrm{~kJ} / \mathrm{mol}$, respectively. However, in the presence of carboxylated CNTs, the heat of reaction increased to 61.7 $\mathrm{kJ} / \mathrm{mol}$, indicating a different cure mechanism. Carboxilated CNTs could facilitate the ring opening and generate an ester bond and an alcohol group; whereas the fluorinated CNTs appeared to act mainly as an amine curing agent. On the other hand, the rate constants determined by the Kamal model were not affected by the fluorine modifications whereas carboxylated CNTs resulted on a lower constant rate of the curing agent. A similar effect has been observed in the presence of amino functionalized CNTs. For instance, Yan et al. ${ }^{26}$ reported that these amino-CNTs acted as a secondary curing agent, facilitating the primary amine-epoxide reaction. This effect was more sensible at later stages of the curing reaction. In addition, they observed that increasing the concentration of amino CNTs up to $3 \mathrm{wt} . \%$ resulted in an increase of the vitrification degree.

\section{Properties of epoxy nanocomposites}

\subsection{Mechanical properties}

One of the initial aims of adding nanoparticles to epoxy resins was to improve their mechanical properties for structural applications, which became a difficult endeavor, even from the theoretical point of view. Compared to thermoplastics, the shear forces generated while dispersing the CNPs in the thermosets matrix are much lower and the achieved dispersion state has to be maintained during the curing process. In addition, the CNP contribution to the load transfer is more effective in compression $^{28}$, while many of the structural applications of epoxy resins require high mechanical performance in other modes. Nevertheless, notable improvements have been made on the mechanical performance of carbon based epoxy nanocomposites. For instance, Alloui et al. ${ }^{29}$ doubled the Young's modulus and the yield strength of the composite by adding 1 wt.\% of CNT and quadrupled with 4 wt.\% CNT (Figure $3)$. The authors concluded that the reinforcement role is much reduced in the case of $4 \mathrm{wt}$ \% composite, due to the formation of agglomerates and the presence of porosity.

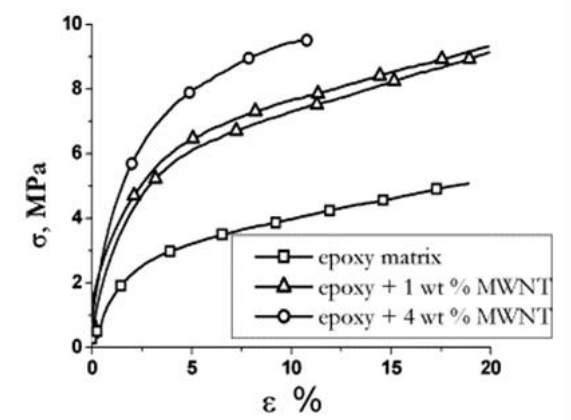

Figure 3. Stress-strain curves of the resin and its CNT composites. Reprinted with permission from Elsevier ${ }^{29}$

Rafiee et al. ${ }^{30}$ comparative studied the mechanical properties of CNTs and graphene nanoplatelets in an epoxy resin at low loading fractions (Figure 4). They observed a $30 \%$ improvement of the Young's modulus with $0.1 \mathrm{wt} . \%$ of graphene. Fatigue behavior was also notable improved by the addition of graphene. The authors concluded that graphene outperformed SWCNT and MWCNT due to several reasons, which included enhanced specific area of the graphene platelets, improved mechanical interlocking/adhesion at the nanofiller/matrix interface and the planar geometry of the graphene platelets. Other authors corroborated the good performance of low loading fractions of graphene nanocomposites ${ }^{9,31-34}$.

As already mentioned, the role of CNT/polymer interface is decisive in the design and development of materials with superior mechanical and multifunctional properties. Good interfacial bonding leads to improved stress transfer from the matrix to the CNPs and imparts higher mechanical strength to the composite ${ }^{35}$. Surface functionalization of CNTs has been demonstrated as an effective method to tailor the CNT/polymer interface ${ }^{36-39}$. 


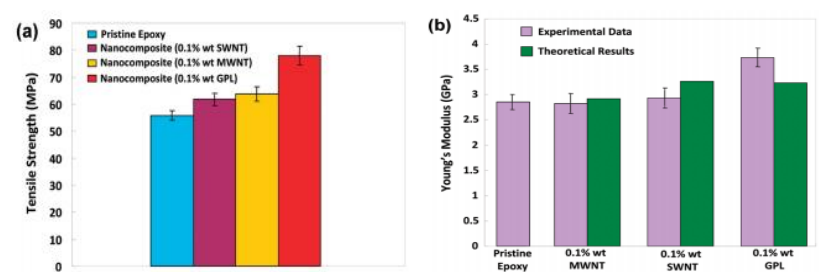

Figure 4. Mechanical comparison of nanocomposites containing CNTs and graphene nanoplatelets, a) tensile strength and b) Young's modulus (HalpinTsai model was used for the theoretical model). Reprinted with permission from American Chemical Society ${ }^{30}$

Covalent and non-covalent approaches have widely been carried out for the surface modification of CNTs. The simplest functionalization consists on the oxidation of the CNTs that results on CNTs bearing oxygen groups. These oxidized CNTs have shown to increase approximately $30 \%$ the modulus and $15 \%$ the tensile strength ${ }^{40,41}$ The oxidized nanotubes can be used as an initial step on subsequent functionalizations, like fluorination $^{40}$, or amination ${ }^{42}$. Amine functionalized CNT/epoxy nanocomposites have also exhibited a $25 \%$ higher modulus at 0.5 wt. $\%$ compared to un-functionalized CNT that only increased a poor $3.2 \%{ }^{42,43}$. Silanized CNTs behaved in a similar way ${ }^{44,45}$.

Rathore et al. ${ }^{46}$ analyzed the role of carboxyl functionalization of CNTs on the interphase of epoxy nanocomposites at high temperatures. It is well known that the environmental temperature has a significant effect on the interfacial durability of polymer nanocomposites, and it usually decreases their mechanical properties. The authors observed that the debonding resistance of the composite can be improved by suitable tailoring the CNT/epoxy interfase through chemical functionalization. The epoxy functionalization of graphene oxide has also led to significant improvements on the ultimate tensile strength of up to $75 \%$ with a 0.25 wt.\% compared to one obtained without the treatment ${ }^{47}$. The authors ascribed the result to a better interfacial interaction between the epoxy functionalized graphene and the matrix observed by fracture surface analysis. Similar functionalization was also carried out for expanded graphite with analogous results. Other chemical routes involving isocyanates, aminobenzoyles and silanes also improved the interaction between graphene and the matrix with success $^{48,49}$

The latest trend is the development of hybrid nanocomposites containing a combination of graphene nanoplatelets and CNTs. These hybrids have so far showed a synergic effect in flexural modulus when the ratio CNT/graphene was $9 / 1$ and $5 / 1$ in uniaxial tension ${ }^{50-52}$. The authors have suggested that the flexible CNTs can interact with graphene to form 3D hybrid structures, which would inhibit face-to-face aggregation of the graphene platelets (Figure 5). The result would be a large surface area of the carbon structure that would be able to entangle the polymer chain of the epoxy matrix and improve the mechanical properties. a
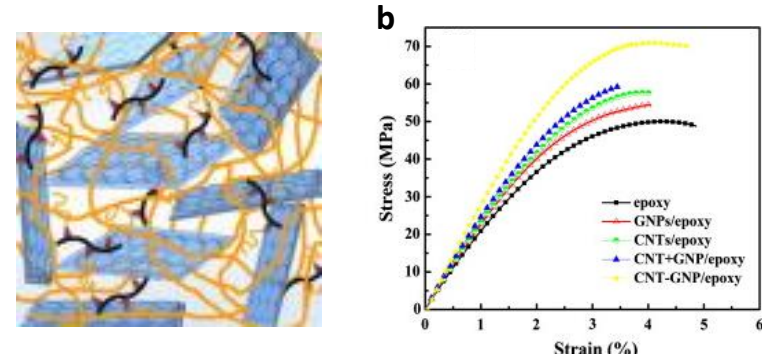

Figure 5. a) Idealized structure of a hybrid nanocomposite containing graphene and CNTs and b) stress-strain curves of the hybrids and nanocomposites. Reprinted with permission from Elsevier ${ }^{51,52}$.

\subsection{Electrical properties}

The extremely high intrinsic electronic and phonon transport of CNPs led to a shift from the initial structural pursuit to a more broad task where the nanocomposites could be imparted with an conductive character. Hence, the CNP/epoxy nanocomposites could act not only as a structural material but also a functional one.

The goal to achieve an electrically conductive material is to disperse the CNPs creating a continuous filler network that guarantees conductive pathways within the polymeric matrix. Such conductive network is usually achieved at a certain concentration of the CNP, which is denoted as the electrical percolation threshold. It is important to consider that the functionalization approaches of CNPs usually improves the final dispersion state of the CNPs, which facilitates the required percolated network, but functionalization processes often alter the molecular structure and/or geometry of the CNPs decreasing their intrinsic electrical properties. In addition, added CNPs usually present a surrounding thin layer of insulating polymer matrix that will be promoted by any surface functionalization, which will be a barrier to the electronic transport through the filler network $^{52,53}$. In conclusion, a specific functionalization can lead either to an improvement on the electrical conductivity or to a decrease on the electric conductivity. Table 1 summarizes the main results obtained on electrical percolation in CNT/epoxy nanocomposites. Sandler et al. $^{55}$ studied the electrical conductivity of CNT epoxy nanocomposites obtaining very low percolation threshold of 0.0025 wt.\% for CVD MWCNTs (Figure 6). Since the first publication on the subject in $1999^{56}$, a huge number of papers dealing with the electrical properties of CNT/epoxy nanocomposites can be found in the literature (see Table 1). In the case of graphene nanocomposites, we find a higher percolation threshold than with CNTs nanocomposites. In general, the electrical percolation network is found in the range of $1-2$ wt.\%. Recently, Li et al. ${ }^{57}$, prepared graphene/epoxy nanocomposites with a relatively low percolation threshold of 0.52 vol. $\%$ and a high electrical conductivity of $10^{-2} \mathrm{~S} / \mathrm{m}$ at 3 wt.\% GNP. The authors produced the nanocomposites in-situ through the process of three-roll milling with high conversion of graphite to graphene nanoplatelets with average aspect ratios of 
300-1000 and thickness of 5-17 nm, without the need of any additives, solvents, compatibilizers or chemical treatments.

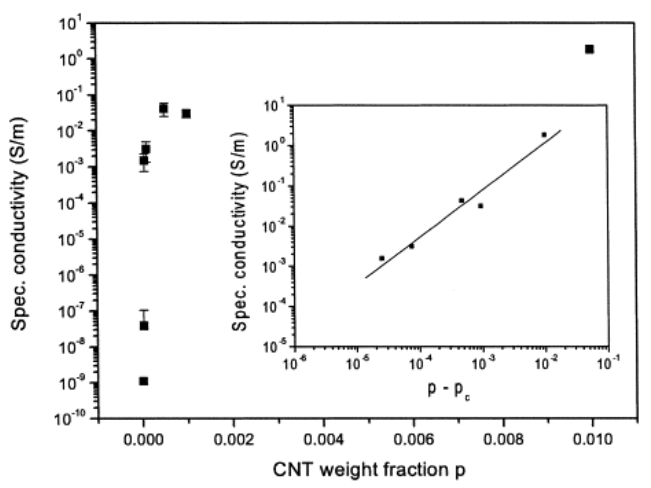

Figure 6. Conductivity as a function of wt.\% of CNT (p). The insert shows a $\log -\log$ plot of the conductivity as a function of $p-p c, p c$ is the percolation threshold. Reprinted with permission from Elsevier ${ }^{55}$.

The electromagnetic interference shielding effect (EMI) of graphene has also been measured and probed that the shielding effectiveness of the nanocomposite increases with the loading of graphene, which is mainly attributed to the formation of conducting interconnected graphene-based sheets networks in the insulating epoxy matrix ${ }^{58-61}$. The target value of the EMI shielding effectiveness needed for commercial applications is around $20 \mathrm{~dB}$, value that was obtained for a concentration of $15 \mathrm{wt} . \%$ of graphene as shown in Figure 7.

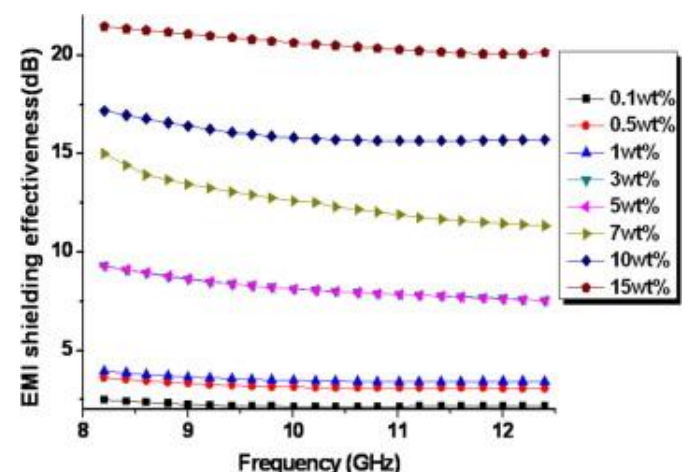

Figure 7. EMI shielding effectiveness for epoxy/graphene nanocomposites. Reprinted with permission from Elsevier ${ }^{58}$
Table 1. Summary of the experimental results concerning the electrical properties of carbon nanoparticles/epoxy nanocomposites.

\begin{tabular}{|c|c|c|c|c|c|}
\hline Filler & Funct. & $\begin{array}{l}\text { Dispersion } \\
\text { method }\end{array}$ & $\begin{array}{c}p_{c} \\
(w t . \%)\end{array}$ & $\begin{array}{c}\sigma_{\max } \\
(\mathrm{S} / \mathrm{m})\end{array}$ & \\
\hline MWCNT & - & Stirring & 0.0021 & $10^{-3} @ 0.01$ wt.\% & 62 \\
\hline MWCNT & - & Stirring & 0.0025 & 2.10@1 wt.\% & 55 \\
\hline MWCNT & - & Stirring & 0.0025 & 4.10-1@0.5 wt.\% & 63 \\
\hline MWCNT & - & Stirring & 0.0039 & 2.10-4@0.01 wt.\% & 63 \\
\hline SWCNT & - & Sonication & 0.005 & 2.10²@0.1 wt.\% & 64 \\
\hline MWCNT & - & Stirring & 0.011 & 4.10-1@1 wt.\% & 65 \\
\hline MWCNT & - & $\begin{array}{l}\text { Sonication + } \\
\text { stirring }\end{array}$ & 0.03 & 5.10-1@0.15 wt.\% & 56 \\
\hline MWCNT & - & $\begin{array}{l}\text { Calendering } \\
\text { + stirring }\end{array}$ & 0.03 & 1.10-2@0.3 wt.\% & 6 \\
\hline MWCNT & Acid & Sonication & 0.034 & 1·10-1@2 wt.\% & 66 \\
\hline SWCNT & - & $\begin{array}{l}\text { Sonication + } \\
\text { stirring }\end{array}$ & 0.04 & 1·10@ wt.\% & 67 \\
\hline SWCNT & Thermal ox. & $\begin{array}{l}\text { Sonication }+ \\
\text { pump }\end{array}$ & 0.074 & 1.10³@0.2 wt.\% & 68 \\
\hline SWCNT & Acid & Stirring & 0.08 & 2.10-2@0.4 wt.\% & 69 \\
\hline SWCNT & Acid & Sonication & 0.1 & 2.10-6@0.1 wt.\% & 70 \\
\hline MWCNT & - & Sonication & 0.1 & 2.10-1@1 wt.\% & 71 \\
\hline DWCNT & - & $\begin{array}{l}\text { Calendering } \\
\text { + stirring }\end{array}$ & 0.15 & $1.10^{-2} @ 0.6$ wt.\% & 6 \\
\hline MWCNT & Amine & $\begin{array}{l}\text { Calendering } \\
+ \text { stirring }\end{array}$ & 0.25 & $1 \cdot 10^{-2} @ 0.6$ wt.\% & 6 \\
\hline DWCNT & Amine & $\begin{array}{l}\text { Calendering } \\
+ \text { stirring }\end{array}$ & 0.25 & 3.10-4@0.6 wt.\% & 6 \\
\hline MWCNT & $\mathrm{UV} / \mathrm{O}_{3}$ & Sonication & 0.27 & 2.10-2@1 wt.\% & 71 \\
\hline SWCNT & - & Infiltration & 0.3 & 5.10-1@3 wt.\% & 72 \\
\hline SWCNT & - & $\begin{array}{l}\text { Sonication + } \\
\text { stirring }\end{array}$ & 0.3 & $1 \cdot 10^{-2} @ 2.5$ wt.\% & 73 \\
\hline SWCNT & - & Manual & 0.6 & 1.10-2 @14 wt.\% & 74 \\
\hline MWCNT & - & Stirring & 0.6 & 5.10-3@10wt.\% & 75 \\
\hline MWCNT & - & Stirring & 0.7 & 5.10 @4 wt.\% & $2 y$ \\
\hline MWCNT & Acid & $\begin{array}{l}\text { Sonication + } \\
\text { stirring }\end{array}$ & 3.5 & $1 \cdot 10^{-5} @ 8$ wt.\% & 76 \\
\hline MWCNT & - & $\begin{array}{l}\text { Calendering } \\
+ \text { stirring }\end{array}$ & $<0.5$ & 3.10-2@2 wt.\% & 77 \\
\hline MWCNT & - & $\begin{array}{l}\text { Sonication + } \\
\text { stirring }\end{array}$ & $<0.5$ & 3.10-1@1.5 wt.\% & 78 \\
\hline MWCNT & - & Calendering & - & 1.10-2@0.5 wt.\% & $7 y$ \\
\hline SWCNT & Acid & Sonication & 0.05 & 1.10-4@5 wt.\% & 80 \\
\hline MWCNT & Surfactant & Sonication & 0.06 & 1.10-2@0.25 wt.\% & 81 \\
\hline MWCNT & - & & 2.7 & $1 \cdot 10^{-5} @ 5$ wt.\% & 82 \\
\hline MWCNT & $\begin{array}{c}\text { Non- } \\
\text { covalent }\end{array}$ & Sonication & 0.15 & $1 \cdot 10^{-6} @ 0.25$ wt.\% & 36 \\
\hline GNP & - & Calandering & 0.52 & 1.10-2@3.0 wt.\% & 57 \\
\hline MWCNT & - & Sonication & 0.20 & $1 \cdot 10^{-5} @ 1.0$ wol.\% & 83 \\
\hline GNP & - & Sonication & 0.10 & 1.10-2@1.0 wol.\% & 84 \\
\hline GNP & - & Sonicación & 0.6 & 1.10-6@2.0 wol.\% & 85 \\
\hline
\end{tabular}




\subsection{Thermal conductivity}

As for the electrical conductivity, the thermal conductivity $(\kappa)$ enhancement of CNP/epoxy nanocomposites strongly depends on the formation of a conductive filler network through the matrix. Researchers have revealed two main issues associated with CNPs/polymer nanocomposites for heat transfer: the first one is that CNPs tend to aggregate into ropes or bundles and the inert graphite-like surface, causing poor dispersion; the second is related to the high interfacial thermal resistance caused by the phonon mismatch at the interface of the CNPs and the polymer, leading to severe phonon scattering and a drastic reduction of thermal transport properties ${ }^{86,87}$. In addition, the thermal transport through the CNP network by phonons is strongly hindered by the gaps between adjacent particles. Hence, these issues have hindered the attainment of CNP/polymer nanocomposites with high thermal conductivity. Biercuk et al. ${ }^{88}$ obtained large improvements of the $K$ at room temperature, of about $120 \%$, at 1 wt.\% loading of SWCNT. The authors observed that the enhancement in SWCNT/epoxy samples rised much more rapidly than in CNF/epoxy composites (Figure 8). Similar results can be found elsewhere ${ }^{89-105}$.

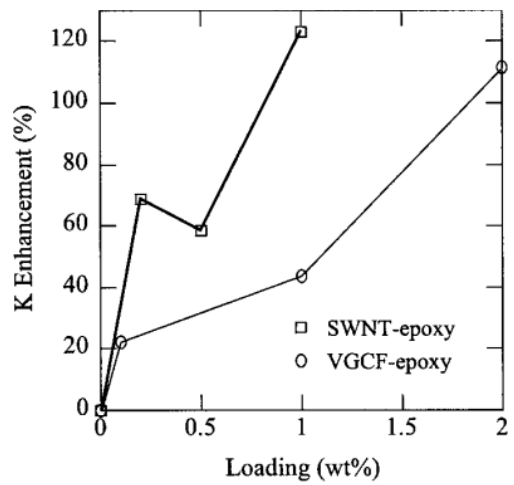

Figure 8. $\kappa$ enhancement as function of SWNT and CNF loading. Reprinted with permission from AIP Publishing LLC $^{88}$

However, the absolute values of the thermal conductivity of CNPs/epoxy nanocomposites are far below the values expected from the exceptionally high thermal conductivity of the nanofillers. Such low efficiency is attributed to a poor thermal conductance interface between the nanofiller and the epoxy resin, due to their weak interactions. Several surface functionalization have been used investigated to reduce the phonon vibrational modes ${ }^{93,106-}$ 108. Recently, Zhao et al. ${ }^{93}$ reported a $189 \%$ increase of the thermal conductivity of a 10 wt.\% epoxy-functionalized graphene (G-EP system, reaching values of up to $3.138 \mathrm{~W} / \mathrm{mK}$ (Figure 9). The authors attributed these enhancement to three factors: i) the controllable functionalization ensured the excellent properties of pristine graphene largely inherited by G-EP; ii) the introduced epoxide moieties facilitated G-EP to be well dispersed in epoxy matrix, and iii) the covalent reaction between G-EP and triethylenetetramine hardener strengthened the mechanical adhesion at the filler-matrix interface. However, as with the electronic transport, the functionalization not always improves the heat transfer of the final material. Some studies have reported this negative effect due to a disruption of the phonon transport characteristics of CNPs, increasing phonon scattering at the interface $6,108,109$.

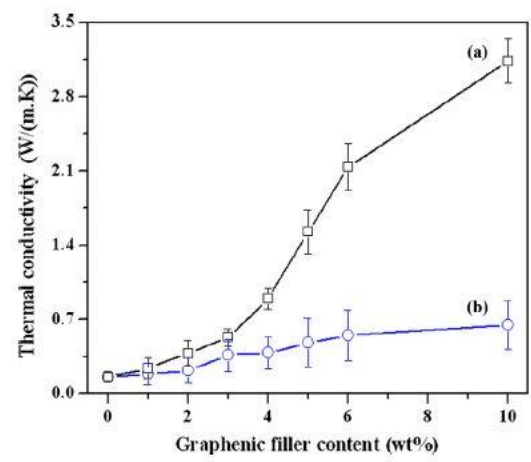

Figure 9. Thermal conductivity of epoxy composites as a function a) G-EP and b) pristine graphene. Reprinted with permission from Elsevier ${ }^{93}$

An exceptional high thermal conductivity has been reported due to the synergic effect of hybrid systems ${ }^{84,102,103,110,111}$. Hybrids of graphene or graphite with MWCNT showed an important synergy and improved $\mathrm{k}$ more than $120 \%$ respect to the neat epoxy resin and $90 \%$ respect to the composites containing individual MWCNT or graphene. Recently, Jiang et al. ${ }^{102}$ have developed a new organic-inorganic hybrid composed of thermally reduced graphene oxide and $\mathrm{ZnO}$ tetrapods functionalized with amine groups (TGO1000@T-ZnO). They first grafted the amine groups to the surface of the $\mathrm{T}-\mathrm{ZnO}$, to facilitated the coating with $\mathrm{GO}$ sheets by forming covalent bonds, and then annealed this system, GO@T-ZnO, at $1000{ }^{\circ} \mathrm{C}$ to reduced the GO. The authors reported a thermal conductivity of $5.06 \mathrm{~W} / \mathrm{mK}$ for the epoxy composites with 65 vol.\% hybrids, which is 27 times higher than the neat epoxy resin. Huang et al. ${ }^{103}$ also fabricated an organic-inorganic hybrid made of hexagonal boron nitride, h-BN and reduced GO. The thermal conductivity of the hybrid is higher than pristine h-BN at the same filler concentration. The conductivity gradually increased when increasing hybrid content, achieving the highest thermal conductivity, of $3.45 \mathrm{~W} / \mathrm{mK}$ for 26.04 vol.\% filler. The authors suggested that h-BN-RGO avoided the agglomeration of h-BN fillers and the formation of voids.

Other promising approach to achieve materials with high thermal conductivity is the preparation of nanostructured composites containing aligned carbon nanoparticles ${ }^{63,112-115}$. For instance, Marconnet et al. ${ }^{114}$ reported axial thermal conductivities of up to $4.87 \mathrm{~W} / \mathrm{mK}$ by adding $16.7 \mathrm{vol} \%$ of aligned MWCNTs. In addition, the authors observed that the CNT alignment resulted in a significantly anisotropic thermal conductivity ( $k_{\text {axial }}$ and $\mathrm{k}_{\text {transverse }} \approx 2-5$ ), which is higher at higher CNT volume fractions (Figure 10). 


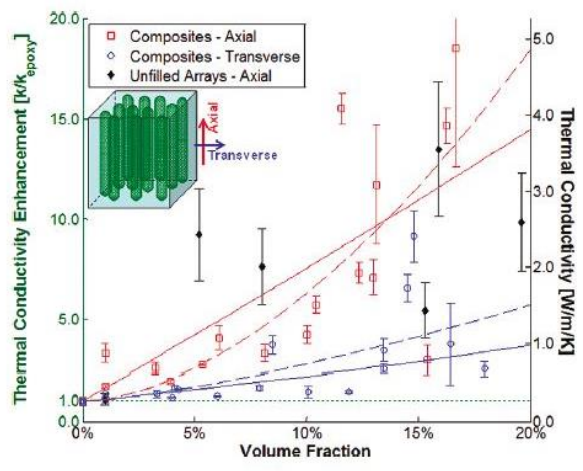

Figure 10. The axial and transverse thermal conductivity of CNT nanocomposites and unfilled CNT forests as a function of volume fraction. Reprinted with permission from American Chemical Society ${ }^{114}$

\section{Conclusions}

We have reviewed the current progress on the production, and properties of epoxy nanocomposites. Although this field has had an important body of research, it has led to limited commercial applications. This is mainly due to lack of a proper understanding of the multiscale interfacial interactions and the resultant network structures, which is primary related to a deficient control of the processing conditions of the epoxy nanocomposites. The full exploitation of graphene filled nanocomposites will be determined both by the level of CNP dispersion and alignment, and by the cost-effective manufacturing of the final material.

\section{Acknowledgements}

The authors gratefully acknowledge the financial support of the State Secretariat for Research, Development and Innovation of the Spanish Ministry of Economía y Competitividad, through the project MAT2016-81138-R. RSH also thanks MINECO for a FPI fellowship.

Keywords: epoxy, nanocomposites, carbon nanotubes, graphene

[1] C. May in Epoy Resins-Chemistry and Technology, Second edition, Ed. Marcel Dekker, New York, 1988

[2] L. Pluart in Recent Advances in Polymer Nanocomposites: Synthesis and characterization, (Eds. S. Thomas, G.E. Zaikov, S.V. Valsaraj, A.P. Meera), VSP, Boston 2010

[3] A.A. Azeez, K.Y. Rhee, S.J. Park, D. Hui, Compost Part B 2013, 45, 308-320

[4] S. Rana, R. Alagirusamy, M. Joshi, J. Reinf. Plast. Comp. 2009, 28, 461-487

[5] P.M. Ajayan, L.S. Schadler, C. Giannaris, A. Rubio, Adv. Mater. 2000, $12,750-753$
[6] F.H. Gojny, M.H.G. Wichmann, U. Köpke, B. Fiedler, K. Schulte, Compos. Sci. Technol. 2004, 64, 2363-2371

[7] E.T. Thostenson, T.W. Chou, Carbon, 2006, 44, 3022-3029

[8] A. Jimenez-Suarez, M. Campo, I. Gaztelumendi, N. Markaide, M. Sanchez, A. Ureña, Compos. Part B 2013, 48, 88-94

[9] J.M. Vazquez-Moreno, V. Yuste-Sanchez, R. Sanchez-Hidalgo, R Verdejo, M.A. Lopez-Manchado, L. Fernández-García, C. Blanco, R. Menéndez, Eur. Polym. J. 2017, 93, 1-7

[10] J.M. Vazquez-Moreno, "Development of hierarchical composites based on carbon fibres and graphene", Doctoral Thesis, Madrid, 2017

[11] S.G. Prolongo, A. Jimenez-Suarez, R. Moriche, A. Ureña, Compos. Sci. Technol. 2013, 86, 185-191

[12] A. Yousefi, P.G. Lafleur, R. Gauvin, Polym. Compos. 1997, 18, 157-168

[13] M. Martin-Gallego, A. Gonzalez-Jimenez, R. Verdejo, M.A. Lopezmanchado, J.L. Valentin, J. Polym. Sci., Part B: Polym. Phys. 2015, 53, 1324-1332

[14] D. Puglia, L. Valentini, J.M. Kenny, J. Appl. Polym. Sci. 2003, 88, 452458

[15] D. Puglia, L. Valentini, I. Armentano, J.M. Kenny, Diamond Relat. Mater. 2003, 12, 827-832

[16] T. Zhou, X. Wang, X. Liu, D. Xiong, Carbon 2009, 47, 1112-1118

[17] K. Tao, S. Yang, J.C. Grunlan, Y.S. Kim, B. Dang, Y. Deng, R.L. Thomas, B. L. Wilson, X. Wei, J. Appl. Polym. Sci. 2006, 102, 52485254

[18] I. Ventura, A. Rahaman, G. Lubineau J. Appl. Polym. Sci. 2013, 130, 2722-2733

[19] M.R. Saeb, H. Rastin, M. Nonahal, M. Ghaffari, A. Jannesari, K. Formela, J. Appl. Polym. Sci. 2017, 45221-45230

[20] J.H. Sul, B.G. Prusty, A. Crosky, Polym. Compos. 2017, 1873-1880

[21] M.G. Prolongo, C. Salom, C. Arribas, M. Sánchez-Cabezudo, R.M. Masegosa, S.G. Prolongo, J. Therm. Anal. Calorim. 2016, 125, 629-636

[22] C. Botas, P. Alvarez, P. Blanco, M. Granda, C. Blanco, R. Santamaria L.J. Romasanta, R. Verdejo, M.A. Lopez-Manchado, R. Menendez, Carbon, 2013, 65, 156-164

[23] S.L. Qiu, C.S. Wang, Y.T. Wang, C.G. Liu, X.Y. Chen, Exp. Polym. Lett. 2011, 5, 809-818

[24] M. Abdalla, D. Dean, D. Adibempe, E. Nyairo, P. Robinson, G. Thompson, Polymer 2007, 48, 5662-5670

[25] M. Abdalla, D. Dean, P. Robinson, E. Nyairo, Polymer 2008, 49, 33103317

[26] K. Yang, M. Gu, Y. Jin, J. Appl. Polym. Sci. 2008, 110, 2980-2988

[27] M.R. Saeb, E. Bakhshandeh, H.A. Khonakdar, E. Mäder, C. Scheffler, G. Heinrich, Sci. World J. 2103, 703708

[28] L.S. Schadler, S.C. Giannaris, P.M. Ajayan, Appl. Phys. Lett. 1998, 73, 3842-3844

[29] A. Allaoui, S. Bai, H.M. Cheng, J.B. Bai, Compos. Sci. Technol. 2002, 62, 1993-1998

[30] M.A. Rafiee, J. Rafiee, Z. Wang, H. Song, Z.Z. Yu, N. Koratkar, ACS Nano 2009, 3, 3884-3890

[31] D.R. Bortz, E.G. Heras, I. Martin-Gullon, Macromolecules 2011, 45, 238-245

[32] A.S. Wajid, H.S.T. Ahmed, S. Das, F. Irin, A.F. Jankowski, M.J. Green, Macromol. Mat. Eng. 2013, 298, 339-347

[33] M. Martin-Gallego, M.M: Bernal, M. Hernandez, R. Verdejo, M.A Lopez-Manchado, Eur. Polym. J. 2013, 49, 1347-1353

[34] F. Wang, L.T. Drzal, Y. Qin, Z. Huang, J. Mat. Sci. 2015, 50, 1082-1093

[35] P.C. Ma, N.A. Siddiqui, G. Marom, J.K. Kim, Compos. Part A 2010, 41, 1345-1367

[36] R. Liu, Y. Chen, Q. Ma, J. Luo, W. Wei, X. Liu, J. Appl. Polym. Sci. 2017, 45022-45031

[37] E.Y. Choi, L.W. Choi, C.K. Kim, Carbon 2015, 95, 91-99

[38] K.Y. Cho, Y.S. Yeon, H.Y. Seo, Y. H. Park, H.N. Jang, K.Y. Baek, H.G. Yoon, ACS Appl. Mat. Interf. 2015, 7, 9841-9850

[39] A. Ezzedine, Z. Chen, K.S. Schanze, N.M. Khashab, ACS Appl. Mat. Interf. 2015, 7, 12903-12913 
[40] J. Zhu, J.D. Kim, H. Peng, J. Margrave, V. Khabashesku, E. Barrera, Nano Lett. 2003, 3, 1107-1113

[41] X.F. Yi, A.K. Mishra, N.H. Kim, B.C. Ku, J.H. Lee, Compos. Part A 2013, $49,58-67$

[42] L.J. Cui, Y.B. Wang, W.J. Xiu, W.Y. Wang, L.H. Xu, X.B. Xu, Y. Meng, L.Y. Li, J. Gao, L.T. Chen, H.Z. Geng, Mater Design 2003, 49, 279-284

[43] S. Wang, Z.Y. Liang, T. Liu, B. Wang, C. Zhang, Z. Wang, T. Liang, B. Liu, C. Wang, Nanotechnol. 2006, 17, 1551-1557

[44] J.H. Lee, K.Y. Rhee, J. Nanosci. Nanotechnol. 2011, 11, 275-280

[45] J.H. Lee, K.Y. Rhee, S. Park, Compos. Part A. 2011, 42, 478-483

[46] D.K. Rathore, R.K. Prusty, B.C. Ray, J. Appl. Polym. Sci. 2003, 44 5893-5899

[47] Y.J. Wan, L.C. Tang, L.X. Gong, D. Yan, Y.B. Li, L.B. Wu, J.X. Jiang, G.Q. Lai, Carbon, 2014, 69, 467-480

[48] K. Liu, S. Chen, Y. Luo, D. Jia, H. Gao, G. Hu, L. Liu, Compos. Sci. Technol. 2013, 88, 84-91

[49] T. Jiang, T. Kuila, N.H. Kim, B.C. Ku, J.H. Lee, Compos. Sci. Technol. 2013, 79, 115-125

[50] S. Chatterjee, F. Nafezarefi, N.H. Tai, L. Schlagenhauf, F.A. Nüesch, B.T.T. Chu, Carbon 2012, 50, 5380-5386

[51] S.Y. Yang, W.N. Lin, Y.L. Huang, H.W. Tien, J.Y. Wang, C.C.M. Ma, S.M. Li, Y.S. Wang, Carbon 2011, 49, 793-803

[52] W. Li, A. Dichiara, J. Bai, Compos. Sci. Technol. 2013, 74, 221-227

[53] G.A.J. Amaratunga, E. Kymakis, J. Appl. Phys. 2006, 99, 084302

[54] C. Li, E. Thostenson, T.W. Choi, Appl. Phys. Lett. 2007, 91, 223114

[55] J.K. W. Sandler, J.E. Kirk, I.A. Kinloch, M.S.P. Shaffer, A.H. Windle, Polymer 2003, 44, 5893-5899

[56] J. Sandler, M.S.P. Shaffer, T Prasse, W Bauhofer, K Schulte, A.H Windle, Polymer 1999, 40, 5967-5971

[57] Y. Li, H. Zhang, H. Porwal, Z. Huang, E. Bilotti, T. Peijs, Compos. Part A 2017, 95, 229-236

[58] J. Liang, Y. Wang, Y. Huang, Y. Ma, Z. Liu, J. Cai, C. Zhang, H. Gao, Y. Chen, Carbon 2009, 47, 922-925

[59] N. Yousefi, X. Sun, X. Lin, X. Shen, J. Jia, B. Zhang, B. Tang, M. Chan, J.K. Kim, Adv. Mater. 2014, 26, 5480-5487

[60] J. Gu, C. Liang, X. Zhao, B. Gan, H. Qiu, Y. Guo, X. Yang, Q. Zhang, D.Y. Wang, Compos. Sci. Technol. 2017, 139, 83-89

[61] Y. Jiang, R. Sun, H.B. Zhang, P. Min, D. Yang, Z.Z. Yu, Compos. Part A 2017, 94, 104-112

[62] C.A. Martin, J.K.W. Sandler, M.S.P. Shaffer, M.K. Schwarz, W. Bauhofer, K. Schulte, A.H. Windle, Compos. Sci. Technol. 2004, 64 2309-2316

[63] A. Moisala, Q. Li, I.A. Kinloch, A.H. Windle, Compos. Sci. Technol. 2006, 66, 1285-1288

[64] M.B. Bryning, M.F. Islam, J.M. Kikkawa, A.G. Yodh, Adv. Mater, 2005 17, 1186-1191

[65] J.Z. Kovacs, B.S. Velagala, K. Schulte, W. Bauhofer, Compos. Sci. Technol. 2007, 67, 922-928

[66] Y.J. Kim, T.S. Shin, H.D. Choi, J.H. Kwon, Y.C. Chung, H.G. Yoon, Carbon 2005, 43, 23-30

[67] A. Yu, M.E. Itkis, E. Bekyarova, R.C. Haddon, Appl. Phys. Lett. 2006 89, 133102-133105

[68] B. Kim, J. Lee, I. Yu, J. Appl. Phys. 2003, 94, 6724-6728

[69] S. Barrau, P. Demont, C. Maraval, A. Bernes, C. Lacabanne, Macromol. Rapid Comm. 2005, 26, 390-394

[70] J.M. Brown, D.P. Anderson, R.S. Justice, K. Lafdi, M. Belfor, K.L Strong, D.W. Schaefer, Polymer 2005, 46, 10854-10865

[71] J. Li, P.C. Ma, W.S. Chow, C.K. To, B.Z. Tang, J.K. Kim, Adv. Funct Mater. 2007, 17, 3207-3215

[72] F. Du, C. Guthy, T. Kashiwagi, J.E. Fischer, K.I. Winey, J. Polym. Sci. Part B: Polym. Phys. 2006, 44, 1513-1519

[73] S. Barrau, P. Demont, A. Peigney, C. Laurent, C. Lacabanne, Macromolecules 2003, 36, 5187-5194

[74] L. Liu, S. Matitsine, Y.B. Gan, L.F. Chen, L.B. Kong, K.N. Rozanov, J. Appl. Phys. 2007, 101, 94106-94113
[75] S.M. Yuen, C.C.M. Ma, H.H. Wu, H.C. Kuan, W.J. Chen, S.H. Liao, C.W. Hsu, H.L. Wu, J. Appl. Polym. Sci., 2007, 103, 1272-1278

[76] S. Cui, R. Canet, A. Derre, M. Couzi, P. Delhaes, Carbon 2003, 41 797-809

[77] M.H.G. Wichmann, J. Sumfleth, B. Fiedler, F.H. Gojny, K. Schulte, Mech. Compos. Mater. 2006, 42, 395-406

[78] Y.S. Song, J.R. Youn, Carbon 2005, 43, 1378-1385

[79] J. Sumfleth, K. Prehn, S. Wedekind, K.A. Schulte, Compos. Sci. Technol. 2010, 70, 173-180

[80] Q. Wang, J. Dai, W. Li, Z. Wei, J. Jiang,,Compos. Sci. Technol. 2008 68, 1644-1648

[81] Y. Geng, M.Y. Liu, J. Li, X.M. Shi, J.K. Kim, Compos. Part A 2008, 39 1876-1883

[82] S. Boukheir, A. Len, J. Fuzi, V. Kenderes, M.E. Achour, N. Eber, L.C. Costa, A. Oueriagli, A. Outzourhit, J. Appl. Polym. Sci., 2017, 44514 44521

[83] J. Ervina, M. Mariatti, S. Hamdan, Eur. Polym. J. 2017, 74, 2513-2533

[84] Z.A. Ghaleb, M. Mariatti, Z.M. Ariff, J. Reinf. Plast. Compos. 2017, 36, 685-695

[85] Q. Meng, H. Wu, Z. Zhao, S. Araby, S. Lu, J. MA, Compos Part A 2017 92, $42-50$

[86] Z. Han, A. Fina, Prog. Polym. Sci. 2011, 36, 914-944

[87] N. Burger, A. Laachachi, M. Ferriol, M. Lutz, V. Toniazzo, D. Ruch, Prog. Polym. Sci. 2016, 61, 914-944

[88] M.J. Biercuk, M.C. Llaguno, M. Radosavljevic, J.K. Hyun, A.T. Johnson, J.E. Fischer, Appl. Phys. Lett. 2002, 80, 2767-2779

[89] M. Martin-Gallego, R. Verdejo, M. Khayet, J.M. Ortiz de Zarate, M. Essalhi, M.A. Lopez-Manchado, Nanoscale Res Lett 2011, 6, 610-616

[90] C.C. Teng, C.C.M. Ma, C.H. Lu, S.Y. Yang, S.H. Lee, M.C. Hsiao, M.Y Yen, K.C. Chiou, T.M. Lee, Carbon 2011, 49, 5107-5116

[91] S.M. Song, K.H. Park, B.H. Kim, Y.W. Choi, G.H. Jun, D.J. Lee, B.S Kong, K.W. Paik, S. Jeon, S. Adv. Mater. 2013, 25, 732-737

[92] Y. Wang, H.F. Zhan, Y. Xiang, C. Yang, C.M. Wang, Y.Y. Zhang, J. Phys. Chem. C 2015, 119, 12731-12738

[93] S. Zhao, H. Chang, S. Chen, J. Cui, Y. Yan, Eur. Polym. J. 2016, 84 300-312

[94] X. Shen, Z. Wang, Y. Wu, X. Liu, J.K. Kim, Carbon 2016, 108, 412-422

[95] Y. Shen, Z. Wang, Y. Wu, X. Liu, Y.B. He, J.K. Kim, Nano Lett. 2016 16, 3585-3593

[96] T. Ji, Y. Feng, M. Qin, W. Feng, Compos. Part A 2016, 91, 351-369

[97] Y. Sun, B. Tang, W. Huang, S. Wang, Z. Wang, X. Wang, Y. Zhu, C. Tao, Appl. Therm. Eng. 2016, 103, 892-900

[98] J. Gu, X. Yang, Z. Lv, N. Li, C. Liang, Q. Zhang, Int. J. Heat Mass Transfer 2016, 103, 892-900

[99] T. Zhou, F. Liu, K. Suganuma, S. Nagao, RSC Advances 2016, 6, 20621-20628

[100] G.B. Olowojoba, S. Kopsidas, S. Eslava, E.S. Gutierrez, A.J. Kinloch, C. Mattevi, V.G. Rocha, A.C. Taylor, J. Mater. Sci. 2017, 52, 7323-7344

[101] G. Gu, C. Liang, X. Zhao, B. Gan, H. Qiu, Y. Guo, X. Yang, Q. Zhang, D.Y. Wang, Compos. Sci. Technol. 2017, 139, 83-89

[102] Y. Jiang, R. Sun, H.B. Zhang, P. Min, D. Yang, Z.Z. Yu, Compos. Part A 2017, 94, 104-112

[103] T. Huang, X. Zeng, Y. Yao, R. Sun, F. Meng, J. Xu, C. Wong, RSC Advances 2017, 7, 23355-23362

[104] J. Jiang, F. Liu, K. Zhuang, D. Chen, G. Chen, RSC Advances 2017, 7, 40761-40766

[105] R. Metz, L. Diaz, R. Aznar, L. Alvarez, V. Flaud, S. Ananthakumar, J.L. Bantignies, Exp. Heat Transfer 2017, 30, 66-76

[106] T Luo, J.R. Lloyd, Adv. Funct. Mater. 2012, 22, 2495-2502

[107] M. Wang, N. Hu, L. Zhou, C. Yan, Carbon 2015, 85, 414-421

[108] S. Ganguli, A.K. Roy, D.P. Anderson, Carbon 2008, 46, 806-817

[109] M.T. Hung, O.H. Choi, Y.S. Ju, H.T. Hahn, Appl. Phys. Lett. 2006, 89, 023117

[110] A. Yu, P. Ramesh, M.E. Itkis, E. Bekyarova, R.C. Haddon, Adv. Mater 2008, 20, 4740-4744 
[111] H. Im, J. Kim, Carbon 2012, 50, 5429-5440

[112] S. Sinn, S. Ganguli, A.K. Roy, L. Qu, L. Dai, Compos. Sci. Technol. 2008, 68, 658-665

[113] W. Lin, K.S. Moon, C.P. Wong, Adv. Mater 2009, 21, 2421-2424

[114] A.M. Marconnet, N. Yamamoto, M.A. Panzer, B.L. Wardle, K.E. Goodson, ACS Nano 2011, 5, 4818-4825

[115] T. Ji, Y. Feng, M. Qin, W. Fen, Compos. Part A 2016, 91, 351-369 
